TAO, Vol. 15, No. 5, 813-824, December 2004

\title{
Lidar Measurements of Spring Dusts in 2002 at Chung-Li $\left(25^{\circ} \mathrm{N}, 121^{\circ} \mathrm{E}\right)$
}

Chih-Wei Chiang ${ }^{1}$, Wei-Nai Chen ${ }^{1}$, Wen-An Liang ${ }^{1}$, and Jan-Bai Nee ${ }^{1, *}$

(Manuscript received 7 March 2003, in final form 30 September 2003)

\begin{abstract}
Lidar observations have been carried out for the dust storms arrival in Taiwan during the springtime in 2002. The dust occurrence, height distributions and transport processes have been investigated. Lidar measurements revealed the largest and smallest dust storms that attacked Taiwan in 2002. The cases of high concentration of aerosols are investigated by comparing with ground particulate measurements $\left(\mathbf{P M}_{10}\right)$, satellite images, and trajectory studies. Two strong cases were measured by the lidar during the spring time of 2002. The first one was the March 18 - 19 dust event, which was also detected by the ground base instrument. The second one was on March 23, which was measured by lidar as a major event but only weakly detected by ground instruments. By comparing with satellite data and back trajectory studies, we found the March 23 event might be a case of biomass burning originated from Southeast Asia. A correlation of lidar integrated signal with the relative humidity indicates a possibility of modification of dust particles by moisture during the transport process.
\end{abstract}

(Key words: Lidar, Aerosol, Asian dust, Polarization, Backscattering)

\section{INTRODUCTION}

Dust storms generated in arid lands in the northwest China in the spring months now increasingly affect Asian regions. In 2000, there were 12 extremely serious dust storms happened in northern China (Zhou et al. 2002). The number of occurrence has increased significantly in the past twenty years to the extent that the environmental and social impacts have caused great concerns. Dust storms are caused mainly by desertification and surface wind

\footnotetext{
${ }^{1}$ Institute of Physics, National Central University, Chung-Li, Taiwan, ROC

* Corresponding author address: Prof. J. B. Nee, Institute of Physics, National Central University, Chung-Li, Taiwan, ROC;E-mail: jbnee@phy.ncu.edu.tw
} 
erosion. The meteorological conditions to generate the storms require dry and cold air and the pressure gradient. When the surface wind speed is greater than $5 \mathrm{~m} \mathrm{~s}^{-1}$, dust can be lifted into the boundary layer or above (Gillette 1978). Dust storms can then be transported to wide areas even across the Pacific Ocean to reach America (Husar 2001). Thus, the environmental impact of dust storm is becoming a worldwide problem.

Monitoring efforts for the chemical and radiative effects of dust storms, which are largely uncertain, have been pursued in many places. Research efforts are emphasized on combining various ground pollution measurements, atmospheric transport models, storm simulations, and satellite images. The ground-based instruments include sun photometer, nephelometer, sky radiometer in invisible or infrared wavelengths, particle counters, various lidars, among other instruments. Besides these pollution-based instrumentations, meteorological observations are also important. Lidar is a powerful tool for obtaining the vertical profiles of the dust aerosols and clouds covering altitudes from 0 - $30 \mathrm{~km}$ (Reagan et al. 1989). Dust storms are now monitored by various lidar facilities in Asian countries through Asian Lidar Network (Murayama et al. 2001).

In 2002, a joint campaign was called to monitor dust storm occurrences in Taiwan. We participated in the observational activities by using the NCU aerosol lidar. In the four-month period between February and May, dust clouds associated with arriving dust storm warnings were detected on many occasions. Besides normal backscattering lidar measurements, the polarization lidar measurements have also been included to strengthen the dust cloud observations. Combined with ground air pollution particle measurements and satellite images, we have obtained useful information about the occurrences, height distributions and transport processes of these dust events.

\section{LIDAR SYSTEM AND MEASUREMENTS}

Currently, aerosols and dust are measured mostly by using the aerosol lidar system. An aerosol lidar usually employs a visible laser wavelength at $532 \mathrm{~nm}$, or the $2^{\text {nd }}$ harmonics, of a Nd:YAG laser as the transmitter. The NCU lidar consists of a laser transmitter at 532/1064 nm and a Newtonian telescope with a diameter $45 \mathrm{~cm}$, as described in previous papers (Nee et al. 1998; Chen et al. 2002). Figure 1 shows the laser system, including the transmitter and receiver systems. A two-wavelength system is under construction for particle size measurements; however, only the $532 \mathrm{~nm}$ lidar system was used here to measure the vertical profiles of backscattering ratio and extinction. The NCU lidar system has been used to investigate subjects of atmospheric temperature structure and dynamics, in addition to aerosol and clouds since 1993, and dust since 2002 (Nee et al. 1998; Chen et al. 2002).

The lidar polarization measurement is made by detecting the backscattering light in its two components of polarizations, whose parallel or perpendicular directions are defined relative to the outgoing laser beam. Each polarization detector system includes a photomultiplier tube combined with a narrow band interference filter centered at $532 \mathrm{~nm}$ (FWHM $3 \mathrm{~nm}$ ). The signals were recorded from $750 \mathrm{~m}$ to $3 \mathrm{~km}$ with $24 \mathrm{~m}$ resolution.

Normally lidar measures the cloud backscattering ratio, R, defined as follows: 


$$
\mathrm{R}=\left(\beta_{\mathrm{a}}+\beta_{\mathrm{c}}\right) / \beta_{\mathrm{a}},
$$

where $\beta_{\mathrm{a}}$ and $\beta_{\mathrm{c}}$ are respectively the backscattering coefficients of air and cloud particles. The extinction coefficient $\mathrm{k}$, optical depth $\tau_{\mathrm{d}}$, and the transmission $\mathrm{T}$ are defined as follows:

$$
\begin{array}{ll}
\text { extinction } & \mathrm{k}=\mathrm{S}_{\mathrm{a}} \beta, \\
\text { optical depth (thickness) } & \tau_{\mathrm{d}}=\int \mathrm{k}(\mathrm{z}) \mathrm{dz}, \\
\text { transmission } & \mathrm{T}=\exp \left(-\tau_{\mathrm{d}}\right) .
\end{array}
$$

$\mathrm{S}_{\mathrm{a}}$ is a factor called lidar ratio or extinction to backscatter ratio. In lidar research, $\mathrm{S}_{\mathrm{a}}$ is usually determined in calculation or by experimentation (Chen et al. 2002). For dust measurements, we used $S_{a}=50$ for data treatments (Murayama et al. 1999).

The depolarization ratio measurements are made by detecting the backscattered light with its polarizations in parallel and perpendicular to the direction of the outgoing laser light. In a

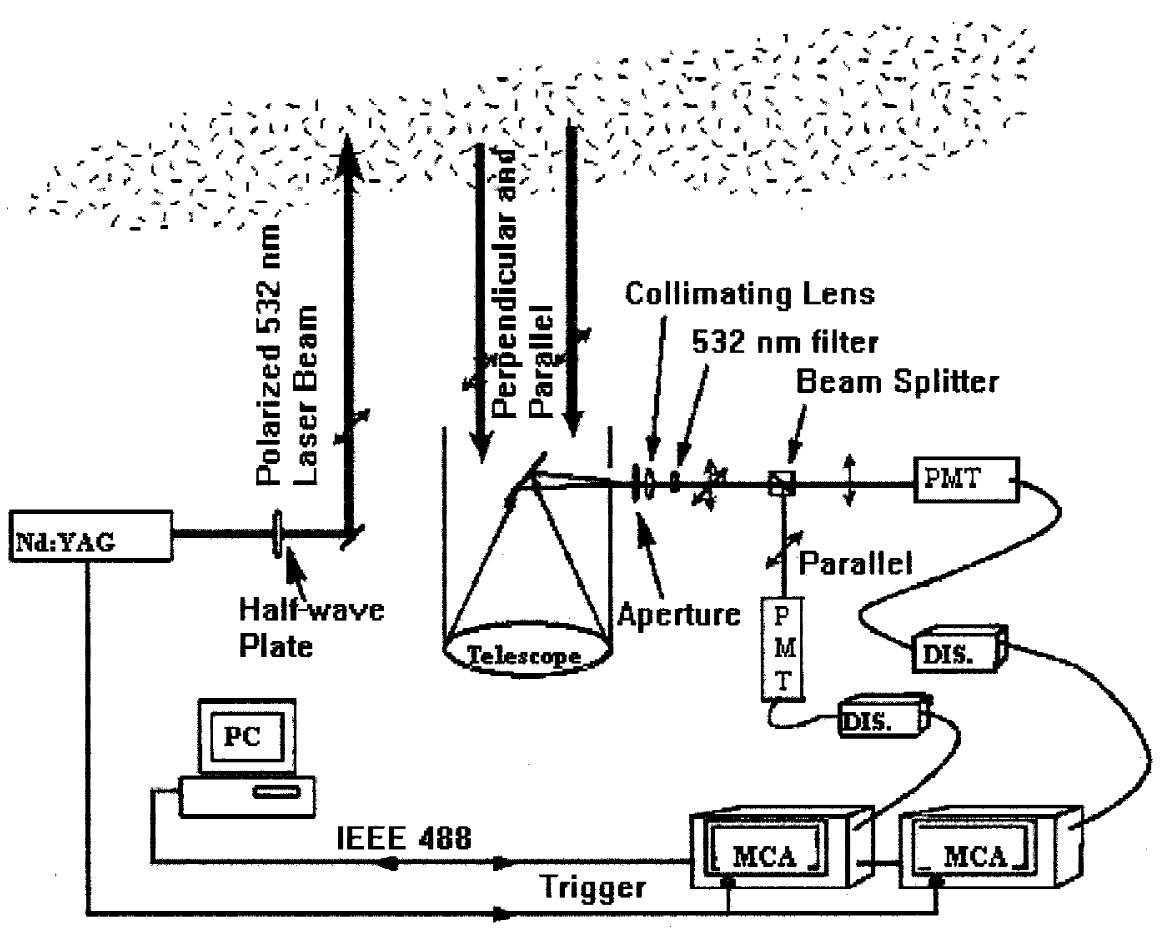

Fig.1. The schematic diagram of NCU lidar system. 
polarization lidar, the depolarization ratio $\delta$ is defined as

$$
\delta=\mathrm{I}_{\perp} / \mathrm{I}_{\|},
$$

where $I_{\|}$and $I_{\perp}$ are the parallel and the perpendicular intensity relative to the outgoing laser beam. For round particles, such as the stratospheric aerosols, the depolarization ratio is close to zero. For particles with unsymmetrical shapes, the depolarization ratio is nonzero. The depolarization ratios of dust aerosols have been found with values 0.2 - 0.5 in various researches (Cairo et al. 1999). The depolarization ratio measurement is essential for understanding the composition of cloud as symmetrical water drops or unsymmetrical cloud and dust particles (Sassen et al. 1992).

\section{RESULTS AND ANALYSES}

\subsection{General Observations:}

In the four month observational period between February and May, ten warnings were issued by the EPA, and five events were detected by lidar, as shown in Table 1 and Fig. 2. It

Table 1. Dust storm events announced by the Environmental Protection Administration (EPA), and detected by NCU lidar in 2002 springtime.

\begin{tabular}{|c|c|c|c|}
\hline $\begin{array}{c}\text { EPA } \\
\text { CASE \# }\end{array}$ & Generation Period & Local affecting period* & $\begin{array}{c}\text { NCU lidar observational } \\
\text { Period }\end{array}$ \\
\hline 5 & $3 / 414 \mathrm{LT} \sim 3 / 614 \mathrm{LT}$ & $3 / 611: 00 \mathrm{LT} \sim 3 / 1008: 00 \mathrm{LT}$ & $\begin{array}{c}3 / 702: 00 \mathrm{LT} \sim 03: 20 \mathrm{LT} \\
3 / 721: 50 \mathrm{LT} \sim 3 / 800: 08 \mathrm{LT} \\
3 / 900: 30 \mathrm{LT} \sim 01: 20 \mathrm{LT} \\
\text { (no polarization mealsurements) }\end{array}$ \\
\hline 6 & $3 / 1308 \mathrm{LT} \sim 3 / 1608 \mathrm{LT}$ & $3 / 18$ 17:00 LT 3/19 07:00 LT & $\begin{array}{l}3 / 1823: 09 \sim 3 / 1903: 31 \mathrm{LT} \\
3 / 1920: 28 \sim 3 / 2002: 30 \mathrm{LT}\end{array}$ \\
\hline 7 & $3 / 1914 \mathrm{LT} \sim 3 / 2214 \mathrm{LT}$ & $3 / 2313: 00 \mathrm{LT}-3 / 2420: 00 \mathrm{LT}$ & $3 / 2319: 54 \sim 3 / 2403: 51 \mathrm{LT}$ \\
\hline 8 & $3 / 2714 \mathrm{LT}-3 / 2908 \mathrm{Lt}$ & No arriving & $\begin{array}{l}3 / 2620: 26 \sim 3 / 2701: 11 \mathrm{LT} \\
3 / 3120: 23 \sim 4 / 0101: 13 \mathrm{LT}\end{array}$ \\
\hline 9 & $4 / 514 \mathrm{LT} \sim 4 / 1014 \mathrm{LT}$ & No effect & \\
\hline 10 & $4 / 1514 \mathrm{LT} \sim 4 / 1714 \mathrm{LT}$ & $4 / 1715: 00 \mathrm{LT} \sim 4 / 1819: 00 \mathrm{LT}$ & $4 / 1923: 40 \sim 4 / 2003: 20 \mathrm{LT}$ \\
\hline
\end{tabular}

* Note: LT: Local Time, based on EPA announcement and TAQM (Taiwan Air Quality Model, C. P. Chen, National Taiwan University). 
was special that in 2002 all dust storms came with front systems such that the weather conditions were generally unsatisfactory for lidar observations because of unclear lower atmosphere with the presences of clouds and fogs in the $1-2 \mathrm{~km}$ height range. NCU lidar was operating at best performance conditions whenever possible. The overcast condition of the lower atmosphere generally interfered with aerosol and cloud detection. However, dust layers often produced backscattering signals a factor of 100 times stronger than normal clouds.

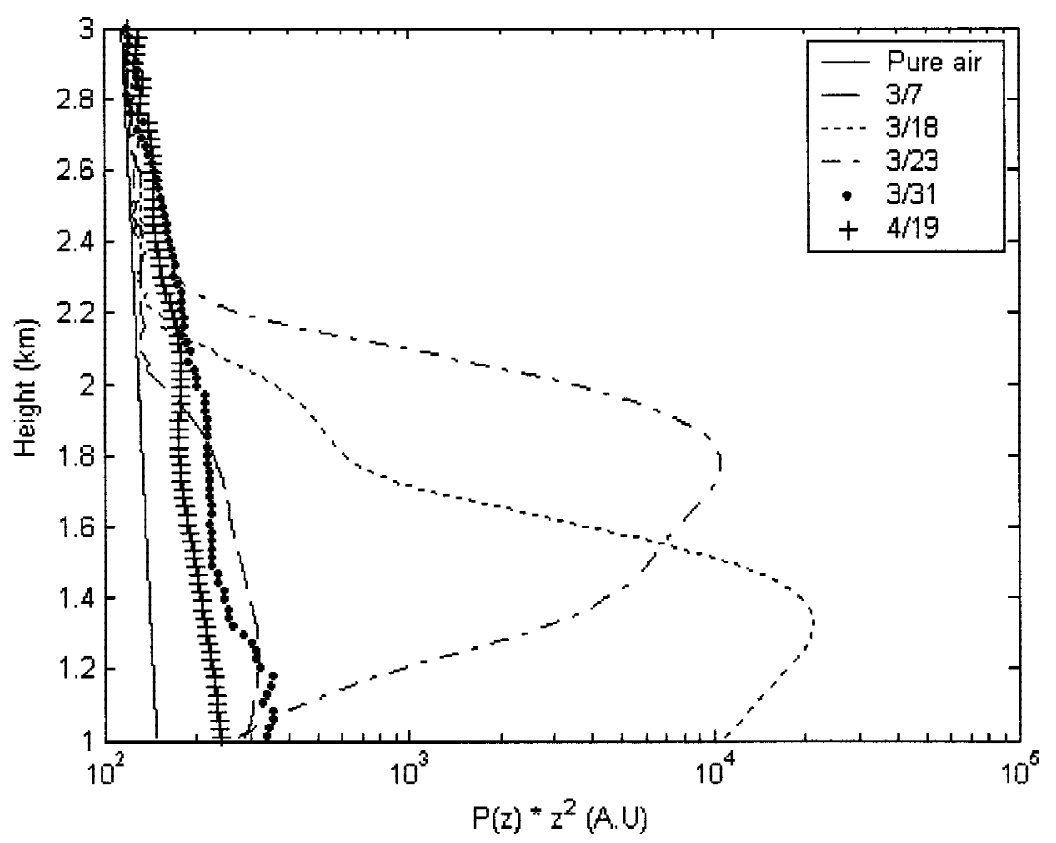

Fig.2. Altitude profiles of 2002 lidar dust backscattering signals occurring on days: $3 / 7,3 / 18,3 / 23,3 / 31,4 / 19$.

Figure 2 shows a comparison of the backscattering signals of five dust storms observed in the months of March to April by lidar. The average dust cloud had a height of about $1.5 \mathrm{~km}$ or so, as we can see from both Figs. 2 and 3. We can immediately find that the March 18 - 19 event was the strongest and the April 19 event the weakest. On March 23 - 24, strong lidar signals were observed despite low pollution measurements by ground instruments (compared with Fig. 5, which is to be discussed in later sections). The dust layer measured on March 23 was relatively higher compared with the boundary layer, which is located at about $1 \mathrm{~km}$. It is therefore possible that the plume was only passing above the boundary layer without descending, or it could come from an alternative source. Figure 3 shows the dust layer changing to $1.8 \mathrm{~km}$ from the beginning $1.4 \mathrm{~km}$. We notice the $1.4 \mathrm{~km}$ layer persisted, but a new layer at $1.8 \mathrm{~km}$ moved into our region associated with weather system. This is related to the nature of a fixedpoint lidar observation. 


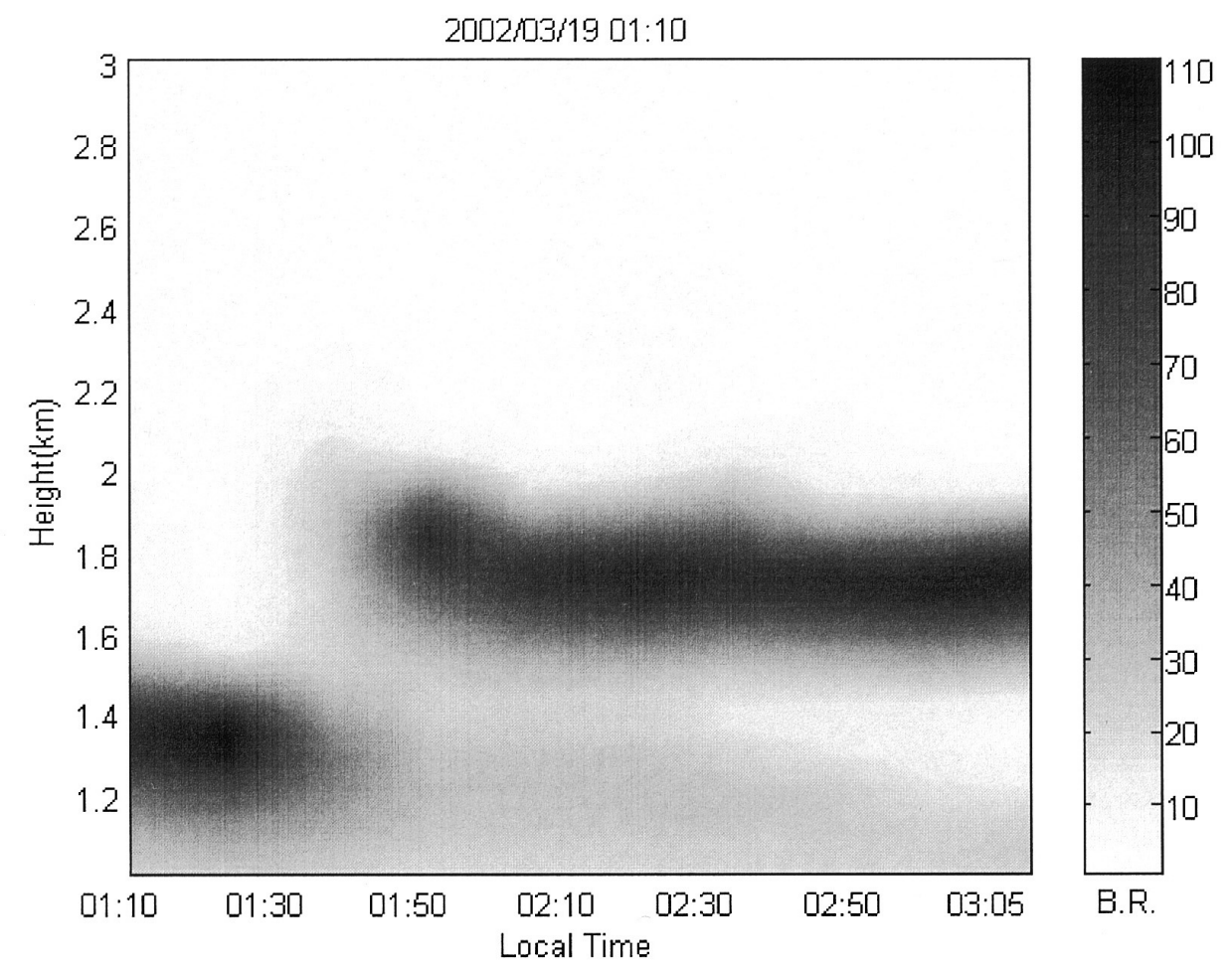

Fig. 3. The dust layers on 2002/3/19 was the strongest lidar dust event measured in 2002. In this figure we can see the largest backscattering ratio was higher than 100.

\subsection{Polarization Measurements}

The polarization lidar is useful in distinguishing dust particles from water vapor or droplets as demonstrated in Fig. 4. In the left panel, Fig. 4a, the parallel polarization channel shows a major cloud layer at $1.5 \mathrm{~km}$ and a weak water cloud at about $1.9 \mathrm{~km}$. The right panel, Fig. 4b, shows the perpendicular polarization channel which indicates the disappearance of the water cloud of the top layer at $1.9 \mathrm{~km}$ as well as layer at the cloud bottom. Figs. $4 \mathrm{c}$ and d are the vertical profiles of the corresponding images showing in Figs. 4a, b. The $1.5 \mathrm{~km}$ cloud in Fig. 4 was likely embedded with sand as we can see by comparing the right panel with the left panel. Based on literature reports, the depolarization ratio for dust cloud often reached 0.3 or more (Sassen et al. 1992; Kwon et al. 1997; Cairo et al. 1999). Table 2 shows results of depolarization ratio $\delta$ measured for dust events of 2002. Our depolarization ratios are generally falling into the range between 0.15 and 0.51 . This shows the non-spherical nature of the dust particles. 


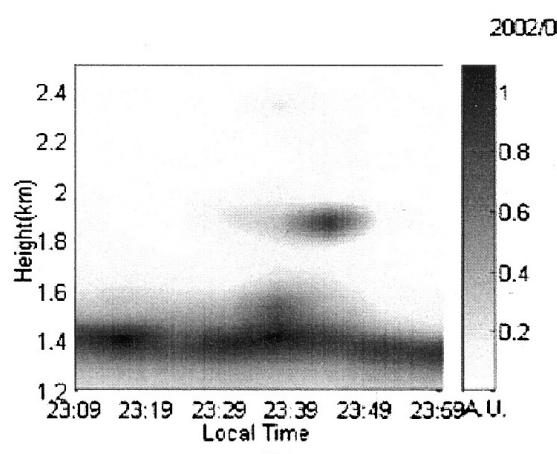

(4a)

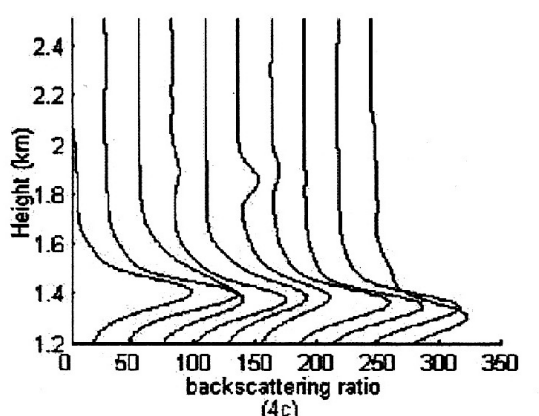

(4c)
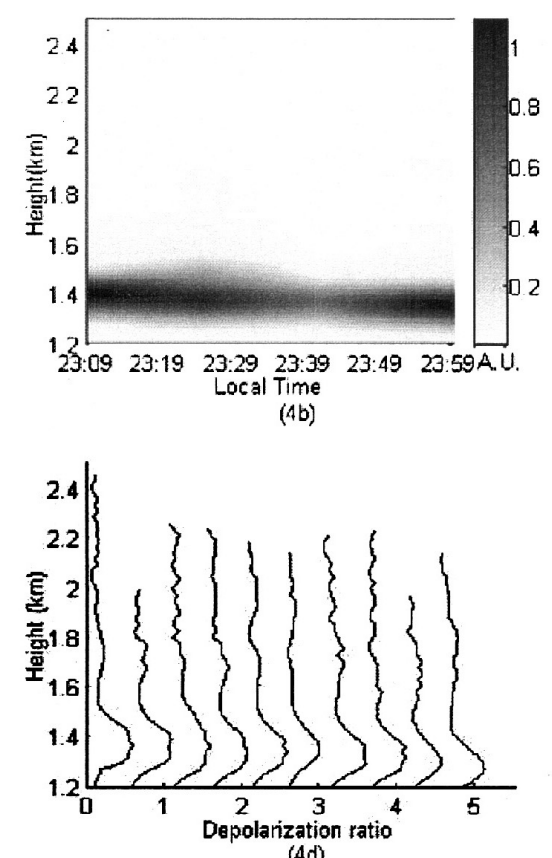

(4d)

Fig. 4. (a) The parallel polarization channel measured a major cloud layer at $1.5 \mathrm{~km}$ and a weak water cloud at about $1.9 \mathrm{~km}$. (b) The measurement of the perpendicular polarization channel indicates the disappearance of the water cloud of the top layer at $1.9 \mathrm{~km}$ as well as layer at the cloud bottom below $1.5 \mathrm{~km}$. (c) and (d) The vertical profiles of the corresponding images showing in Figs. $4 a$ and $b$.

Table 2. The maximum depolarization ratio of dust storm attacked Taiwan

\begin{tabular}{|c|c|c|c|}
\hline Case & Data period* & $\begin{array}{c}\text { Height } \\
(\mathrm{km})\end{array}$ & $\begin{array}{c}\text { Maximum average } \\
\text { depolarization ratio }\end{array}$ \\
\hline 6 & $2002 / 3 / 1823: 09 \sim 00: 39$ & 1.47 & 0.51 \\
\hline 7 & $2002 / 3 / 23 \quad 19: 54 \sim 20: 24$ & 2.25 & 0.45 \\
\hline 8 & $2002 / 3 / 3123: 00 \sim 23: 30$ & 2.18 & 0.22 \\
\hline 10 & $2002 / 4 / 2000: 00 \sim 00: 30$ & 1.42 & 0.18 \\
\hline
\end{tabular}

* The average depolarization ratio was derived from a 30 minute observational period. 


\section{DISCUSSION}

\subsection{Comparisons with $\mathbf{P M}_{10}$ Data and TOMS Image}

The Particulate Matter data with sizes smaller than $10 \mu \mathrm{m}\left(\mathrm{PM}_{10}\right)$ are shown in Fig. 5 and are compared with lidar measurements to give insight about 2002 dusts. As we can see, the strongest $\mathrm{PM}_{10}$ occurred on 3/19 with an amount of $150 \mu \mathrm{gm}^{-3} . \mathrm{PM}_{10}$ was low on $3 / 23$ with

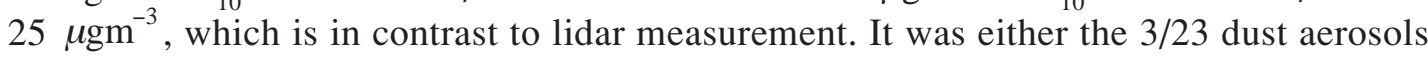
passed without descending, or they were originated from other pollution sources.

TOMS satellite provides daily aerosol index image covering the entire globe. On 3/23 - 3/24, TOMS image showed spreading aerosol layers generated from both North and South China, as shown in Fig. 6. The northern source mostly drifted to Japan, but a small plume was likely moving down, as shown in the picture. This should be desert dust, while the southern source was likely non-dust aerosol, such as biomass produced in southeast China. Both sources might produce aerosol layers arriving Taiwan and nearby areas. But, satellite images show the southern source to be dominant. Thus, the transport of dust is an important issue to be understood.

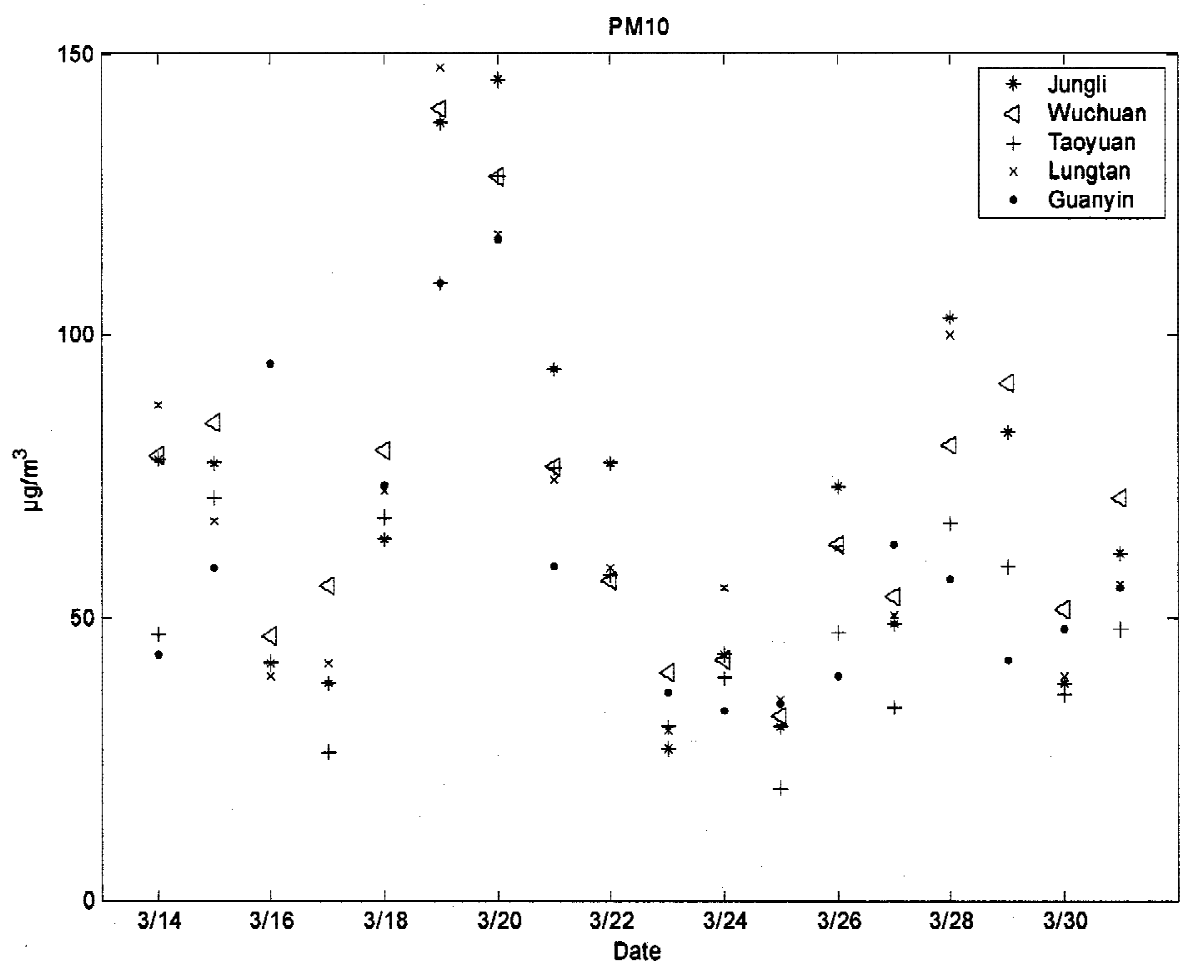

Fig. 5. The $\mathrm{PM}_{10}$ index for dust measurements in March 14 - 20, 2002 (source: EPA monitoring stations nearby NCU). The strongest dust event occurred on March 18 - 20. 


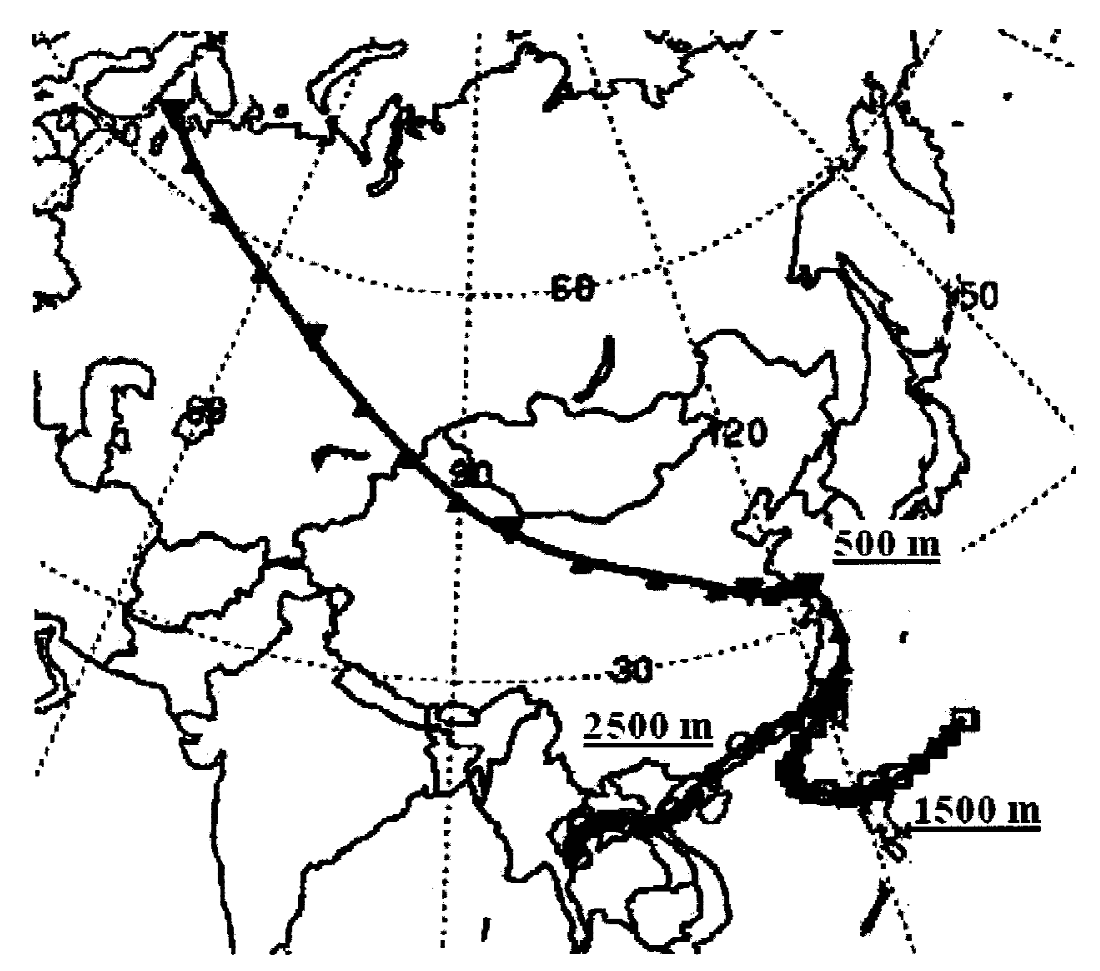

Fig. 7. The HYSPLIT trajectory results for three parcels of air at $500 \mathrm{~m}, 1500 \mathrm{~m}$, and $2500 \mathrm{~m}$ on March 23. The $2500 \mathrm{~m}$ parcel is consistent with TOMS and lidar measurements.

2001). Research efforts of using satellite observations and lidar measurements should be helpful in these regards.

Based on Zhou et al. (2002), the humidity affects the aerosol extinction through modification of particle size distribution and composition. This should have impacts on the radiative problems. The 2002 dust events were usually arriving with front system so that dust particles might be transported within the humid air. In order to understand the humidity effect, the lidar signals are correlated with the relative humidity. As Fig. 8 shows, there is a good correlation of the integrated lidar signal on the 3/18 - 3/19 measurement with the relative humidity data of the date. The humidity data was provided by the Central Weather Bureau based on the radiosonde record. The mechanism should be related to the hygroscopic growth of dust particles.

\section{CONCLUSIONS}

Lidar measurements of the Asian dust storm were carried out in 2002 spring months in March and April. Totally, five arrival cases in 2002 were detected by lidar. The strongest dust 


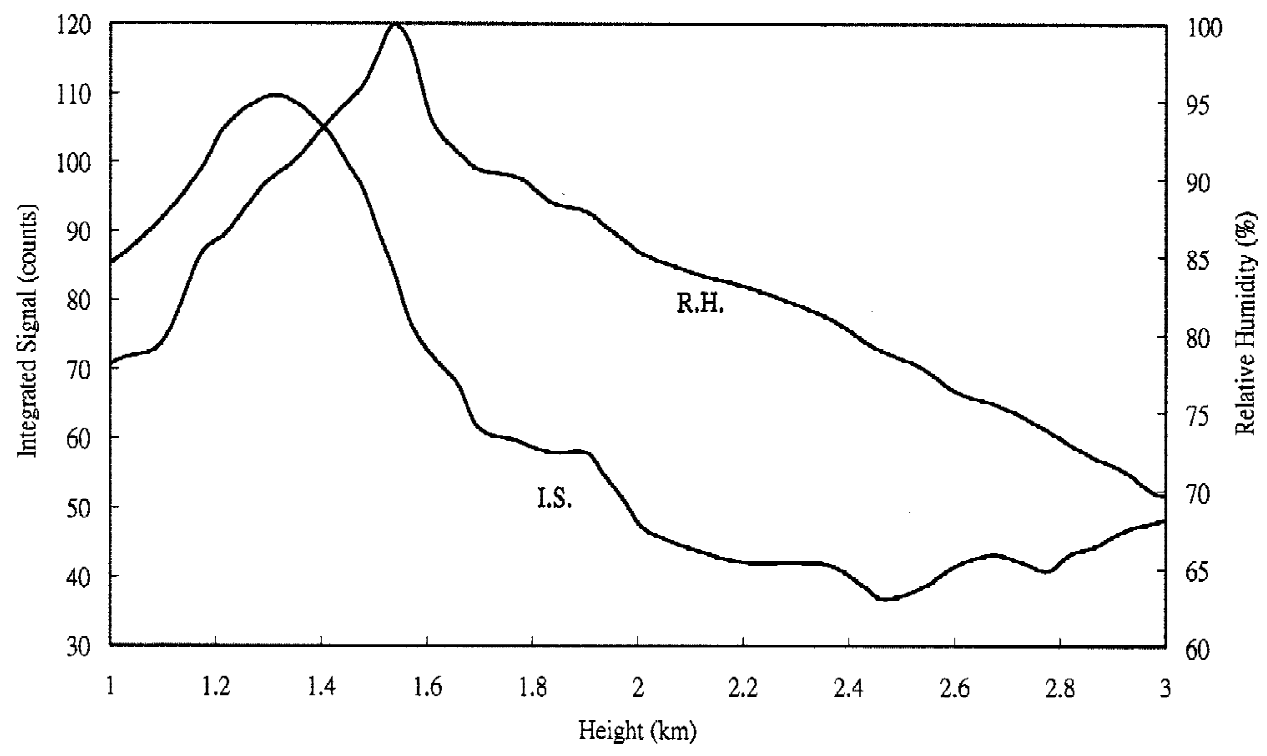

Fig. 8. The correlation of lidar integrated signal (I.S.) with relative humidity (R.H.) from CWB radiosonde data on 3/18.

cloud was detected on 2002/3/19 and the weakest on 2002/4/19. On 2002/3/23, lidar measured strong aerosol/dust layers at $2.2 \mathrm{~km}$. However, ground instrument reported normal values. By comparing with TOMS satellite image and the air parcel back-trajectory, we found this aerosol layer could be due to an alternative source of aerosols such as the biomass burning in Southeast Asia. Polarization lidar measurements found the depolarization ratio ranged between 0.15 and 0.51 and the optical depth were derived from lidar data. The modification of dust aerosol by moisture is investigated.

Acknowledgements This research is supported by the National Science Council, R.O.C. with a grant NSC91-2111-M-008-015 and the Environmental Protection Administration of Taiwan through a contract EPA-91-U1L1-02-109. The authors gratefully acknowledge the NOAASit Trdoutvrd Laboratory (ARL) for the provision of the HYSPLITT transport and dispersion model and READY website (http://www.arl.noaa.gov/ready/hysplit4.html). NOAA AIR RESOURCES LABORATORY, SILVER SPRING, MD, USA.

\section{REFERENCES}

Cairo, F., G. D. Donfrancesco, A. Adriani, L. Pulvirenti, and F. Fierli, 1999: Comparison of various linear depolarization parameters measured by lidar. Appl. Opt., 38, 4425-4432. 
Chen, W. N., C. W. Chiang, and J. B. Nee, 2002: Lidar ratio and depolarization ratio for cirrus clouds. Appl. Opt., 41, 6470-6476.

Gillette, D., 1978: A wind tunnel simulation of the erosion of soil: Effect of soil texture, sandblasting, wind speed, and soil consolidation on the dust production. Atmos. Environ., 12, 1735-1743.

Husar, R. B., D. M. Tratt, B. A. Schichtel, S. R. Falke, F. Li, D. Jaffe, S. Gasso, T. Gill, N.S. Laulainen, F. Lu, M. C. Reheis, Y. Chun, D. Westphal, B. N. Holben, C. Gueymard, I. McKendry, N. Kuring, G. C. Feldman, C. McClain, R. J. Frouin, J. Merrill, D. Du Bois, F. Vignola, T. Murayama, S. Nickovic, W. E. Wilson, K. Sassen, N. Sugimoto, and W. C. Malm, 2001: Asian dust events of April 1998. J. Geophys. Res., 106, 18317-18330.

Kaufman, Y. J., D. Tanre, and O. Boucher, 2002: A satellite view of aerosols in the climate system. Nature, 419, 215-223.

Kwon, S. A., Y. Iwasaka, T. Shibata, and T. Sakai, 1997: Vertical distribution of atmospheric particles and water vapor densities in the free troposphere: Lidar measurement in spring and summer in Nagoya, Japan. Atmos. Environ., 31, 1459-1465.

Murayama, T., H. Okamoto, N. Kaneyasu, H. Kamataki, and K. Miura, 1999 : Application of lidar depolarization measurement in the atmospheric boundary layer : Effects of dust and sea-salt particles. J. Geophys. Res., 104, D24, 31781-31792.

Murayama, T., N. Sugimoto, I. Uno, K. Kinoshita, K. Aoki, N. Hagiwara, Z. Liu, I. Matsui, T. Sakai, T. Shibata, K. Arao, B. J. Sohn, J. G. Won, S. C. Yoon, T. Li, J. Zhou, H. Hu, M. Abo, K. Iokibe, R. Koga, and Y. Iwasaka, 2001: Ground-based network observation of Asian dust events of April 1998 in east Asian.J. Geophys. Res., 106, 18,345-18,359.

Nee, J. B., C. N. Lien, W. N. Chen, and C. I. Lin, 1998: Lidar detection of cirrus cloud in Chung-Li $\left(25^{\circ} \mathrm{N}, 121^{\circ} \mathrm{E}\right)$. J. Atmos. Sci., 55, 2249-2257.

Reagan, J. A., M. P. McCormick, and J. D. Spinhirne, 1989: Lidar sensing of aerosols and clouds in the troposphere and stratosphere. Proc., IEEE 77, 433-448.

Sassen, K., H. Zhao, and G. C. Dodd, 1992: Simulated polarization diversity lidar returs from water and precipitating mixed phase clouds. Appl. Opt., 31, 2914-2923.

Sokolik, I. N., D. M. Winker, G. Bergametti, D. A. Gillette, G. Carmichael, Y. J. Kaufman, L. Gomes, L. Schuetz, and J. E. Penner, 2001: Introduction to special section: Outstanding problems in quantifying the radiative impacts of mineral dust.J. Geophys. Res., 106, 18015-18027.

Tanre, D, Y. J. Kaufman, B. N. Holben, B. Chatenet, A. Karnieli, F. Lavenu, L Blarel, O. Dubovik, L. A. Remer, and A. Smirnov , 2001: Climatology of dust aerosol size distribution and optical properties derived from remotely sensed data in the solar spectrum. J. Geophys. Res., 106, 18205-18217.

Zhou, J., G. Yu, C. Jin, F. Qi, D. Liu, H. Hu, Z. Gong, G. Shi, T. Nakajima, and T. Takamura, 2002: Lidar observations of Asian dust over Hefei, China, in spring 2000.J. Geophys. Res., 107, 4252, doi:10.1029/2001JD000802. 